\title{
Analysis on Sub-Prime Debt Crisis
}

\author{
Zidi Zhang \\ Educhina Bela International High School, Beijing, China
}

\begin{abstract}
Economic crises, such as Subprime Mortgage Crisis in 2008, European Debt Crisis in 2010, and stock market disaster in 2015, have become an essential concern for people and governments. People cannot help wondering what economic crises will bring to our country and life. Why will economic crises bring about these changes? What should people do to deal with these changes? This article interprets the core economic indicators, such as GDP, Inflation, Unemployment Rate, and the mechanism of Philips Curve. Based on the results of data analysis, people will find the relationship between unemployment rate and inflation rate. Finally, role and impact of fiscal and monetary policies in economic crisis will be transparent. As a result, economists can have the optimal way of analyzing the dynamic economic growth [1].
\end{abstract}

\section{INTRODUCTION}

The global financial crisis caused by the U.S. subprime crisis since April 2007 poses great harm to the economy. With the further appearance of losses, its impact on the international economy is still expanding[2]. This paper aims to define the subprime crisis and explore its transmission mechanism-Phillips curve. By analyzing the feasibility of Phillips curve in the subprime debt crisis, people can strengthen the financial supervision and reduce the systematic risk in the future, so there will be a strong enlightening effect on the economy.

\section{REVIEW OF THE PHILIPS CURVE}

The Phillips curve is a single-equation econometric model, named after William Phillips, describing a historical inverse relationship between rates of unemployment and corresponding rates of rises in wages that result within an economy. Stated simply, decreased unemployment, (i.e., increased levels of employment) in an economy will correlate with higher rates of wage rises.

While there is a short run trade-off between unemployment and inflation, it has not been observed in the long run. In 1967 and 1968, Milton Friedman and Edmund Phelps asserted that the Phillips curve was only applicable in the short-run and that in the long-run, inflationary policies would not decrease unemployment. Friedman then correctly predicted that the long-run Phillips curve is now seen as a vertical line at the natural rate of unemployment, where the rate of inflation has no effect on unemployment.

In recent years the slope of the Phillips curve appears to have declined and there has been significant questioning of the usefulness of the Phillips curve in predicting inflation. Nonetheless, the Phillips curve remains the primary framework for understanding and forecasting inflation used in central banks.

The original Phillips curve literature was not based on the unaided application of economic theory. Instead, it was based on empirical generalizations. The Phillips curve equation can be derived from the (short-run) Lucas aggregate supply function. The form of the short-run Phillips curve follows:

$$
\pi=\pi_{e}-b\left(U-U_{n}\right)+v
$$

where $\pi$ and $\pi$ e are the inflation and expected inflation respectively, $\mathrm{b}$ is a positive constant, $\mathrm{U}$ is unemployment, and $U n$ is the natural rate of unemployment. This equation, plotting inflation rate $\pi$ against unemployment $\mathrm{U}$ gives the downward-sloping curve in the diagram that characterizes the Phillips curve.

\section{EMPIRICAL RESULTS}

The author choose and analyze the Phillips Curve in US during Sub-prime Debt Crisis. Data are downloaded from Federal Reserve Bank of ST. Louis. The sample period is from January, 2005 to December, 2012. 


\subsection{Before Sub-prime Debt Crisis}

\begin{tabular}{|c|c|c|}
\hline \multicolumn{3}{|c|}{ G Group: UNTITLED Workfile: 0} \\
\hline \begin{tabular}{l|l|l|l|} 
View & Proc & Object
\end{tabular} & Print Name & $F$ \\
\hline & INFLATION & \\
\hline Mean & 3.267965 & \\
\hline Median & 3.338550 & \\
\hline Maximum & 4.741830 & \\
\hline Minimum & 1.406330 & \\
\hline Std. Dev. & 0.820562 & \\
\hline Skewness & -0.285734 & \\
\hline Kurtosis & 2.149737 & \\
\hline Jarque-Bera & 1.792933 & \\
\hline Probability & 0.408009 & \\
\hline Sum & 133.9866 & \\
\hline Sum Sq. Dev. & 26.93287 & \\
\hline Observations & 41 & \\
\hline
\end{tabular}

Figure 1. Inflation index analysis before Sub-prime Debt Crisis (2005-2008)

\begin{tabular}{|c|c|c|c|c|}
\hline \multicolumn{5}{|c|}{ G Group: UNTITLED } \\
\hline View & Proc & Object & Print & Name \\
\hline & & & \multicolumn{2}{|c|}{ UNEMPLOY. } \\
\hline \multicolumn{3}{|c|}{ Mean } & \multicolumn{2}{|c|}{4.807317} \\
\hline \multicolumn{3}{|c|}{ Median } & \multicolumn{2}{|c|}{4.700000} \\
\hline \multicolumn{3}{|c|}{ Maximum } & \multicolumn{2}{|c|}{5.400000} \\
\hline \multicolumn{3}{|c|}{ Minimum } & \multicolumn{2}{|c|}{4.400000} \\
\hline \multicolumn{3}{|c|}{ Std. Dev. } & \multicolumn{2}{|c|}{0.278738} \\
\hline \multicolumn{3}{|c|}{ Skewness } & \multicolumn{2}{|c|}{0.379559} \\
\hline \multicolumn{3}{|c|}{ Kurtosis } & \multicolumn{2}{|c|}{2.272750} \\
\hline \multicolumn{3}{|c|}{ Jarque-Bera } & \multicolumn{2}{|c|}{1.887967} \\
\hline \multicolumn{3}{|c|}{ Probability } & \multicolumn{2}{|c|}{0.389075} \\
\hline \multicolumn{3}{|l|}{ Sum } & \multicolumn{2}{|c|}{197.1000} \\
\hline \multicolumn{3}{|c|}{ Sum Sq. Dev. } & \multicolumn{2}{|c|}{3.107805} \\
\hline \multicolumn{3}{|c|}{ Observations } & \multicolumn{2}{|c|}{41} \\
\hline
\end{tabular}

Figure 2. Unemployment index analysis before Subprime Debt Crisis(2005-2008)

Here are two sets of data about inflation and unemployment rate before the outbreak of sub-prime Debt Crisis. The author is primarily looking for the term of probability of normal distribution of inflation and unemployment. As shown above, the probability of inflation is 0.408009 and that of unemployment is 0.385079 . Both figures are relatively high. It indicates that the normal distribution of inflation and unemployment is plausible.

\subsection{After Sub-prime Debt Crisis.}

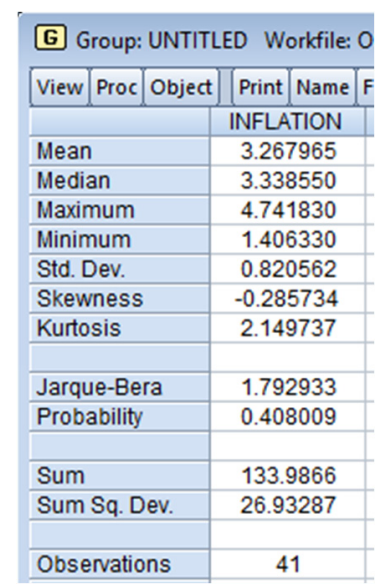

Figure 3. Inflation index analysis after Sub-prime Debt Crisis (2009-2012)

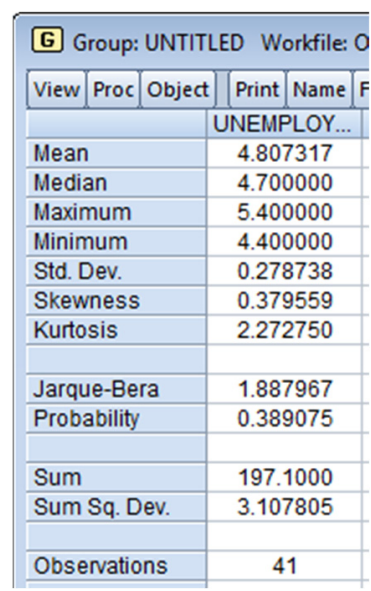

Figure 4. The unemployment index analysis after Subprime Debt Crisis (2009-2012)

Here are two sets of data about inflation and unemployment rate after the outbreak of sub-prime Debt Crisis. The author is primarily looking for the term of probability.

TABLE I. Inflation index and Unemployment index analysis (2005-2008)

\begin{tabular}{|c|c|c|c|c|c|c|}
\hline & Mean & Median & St.Dev & Skewness & Kurtosis & Prob. \\
\hline \multicolumn{7}{|c|}{ Before Crisis } \\
\hline Inflation Rate & 3.2679 & 3.3385 & 1.9412 & -0.1124 & 2.2442 & 0.4080 \\
\hline Unemployment rate & 4.8073 & 4.7000 & 0.2787 & 0.3795 & 2.2727 & 0.3890 \\
\hline \multicolumn{7}{|c|}{ After Crisis } \\
\hline Inflation Rate & 1.8411 & 2.0035 & 1.9412 & -0.1124 & 2.2442 & 0.5729 \\
\hline Unemployment rate & 8.7930 & 9.1000 & 1.2199 & -1.4324 & 3.8910 & 0 \\
\hline
\end{tabular}


By reintegrating the data, the probability of normal distribution is relatively high, which shows a high confidence level of the subsequent estimate result.

\subsection{Scatter}

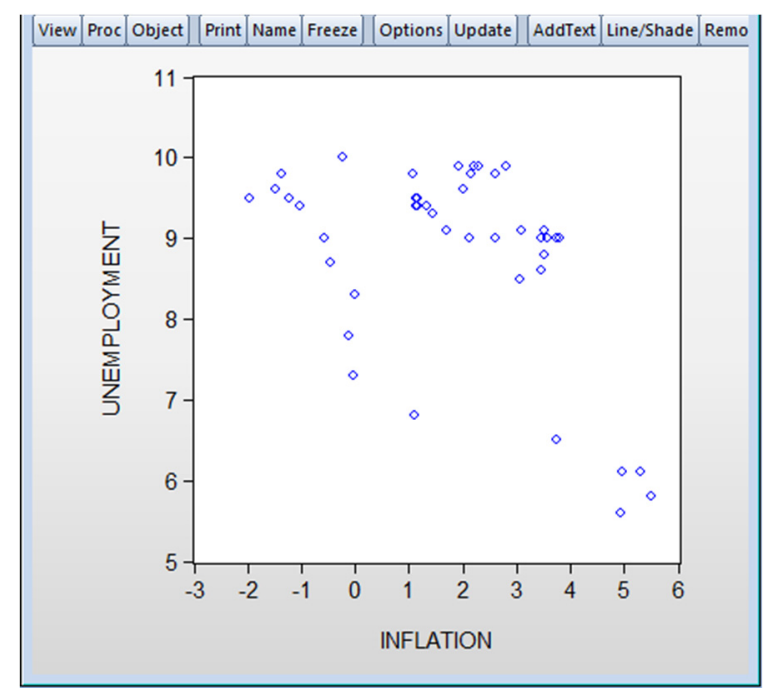

Figure 5. The scatter plot of unemployment and inflation $(2005-2012)$

As shown in the scatter plot, there is a cluster of dots at the top of the graph. Obviously, it is the combination of high inflation and stagnating aggregate output which represents stagflation. However, the dots in the bottom right corner of the graph show that unemployment is foreign to inflation. No matter inflation is high or low, the unemployment rate is low. High inflation is caused by the increase in mortgage lending. Gradually, people's demand will decrease because of high inflation. Factories and companies no longer need too many workers. Consequently, the unemployment rate moves up sharply.

\subsection{Summary}

Before Crisis, unemployment has little to do with inflation, because inflation is rising with house prices rather than with the unemployment rate. So, no matter inflation is high or low, the unemployment rate is low. After the crisis broke out, stagflation happened. Also, the higher prices lead to less demand, so the unemployment rate tends to increase. The unemployment rate and inflation have a negative correlation.

\section{ESTIMATION RESULT}

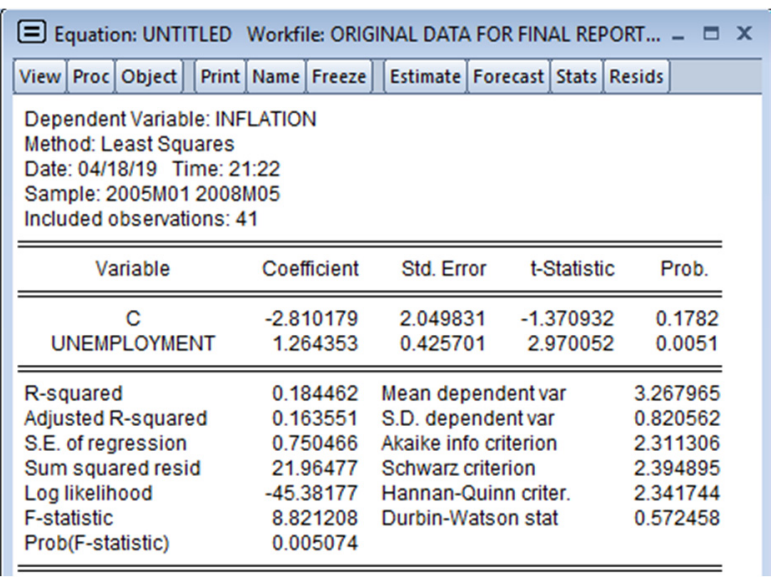

Figure 6. Correlation analysis of inflation rate and unemployment rate before Sub-prime Debt Crisis(20052008)

As shown in fig. 6, the author analyzed the correlation of inflation rate and unemployment rate before sub-prime Debt Crisis. There is a positive relationship between unemployment rate and inflation. This is mostly because of the formula, Inflation $=\mathrm{C}+\mathrm{Beta}$ *unemployment. The Beta here equals to 1.264353 , which is a positive number, so their positive relationship would be proved.

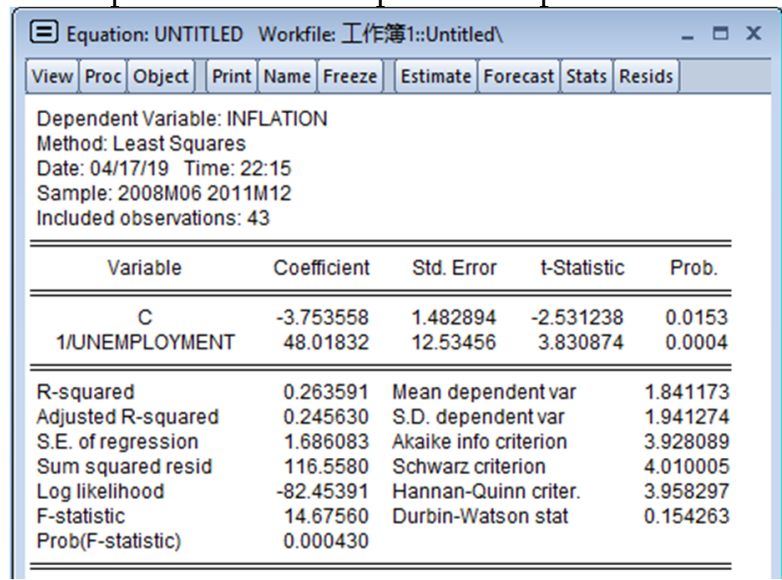

Figure 7. Correlation analysis of inflation rate and unemployment rate after Sub-Prime Debt Crisis (20092012)

Above is the author's analysis of the correlation between inflation rate and unemployment rate. Beta here is a very large number, which equals to 48.01832 . According to the formula, Inflation $=\mathrm{C}+\mathrm{Beta} *(1 /$ unemployment $)$, if Beta is a large number, then both unemployment rate and inflation must be large numbers. Therefore, stagflation exists after the outbreak of Sub-Prime Debt Crisis due to high unemployment rate and high inflation.

\subsection{Summary}

- Function

Inflation $=-2.8101+1.2463 *$ unemployment (before) Inflation $=-3.7535+48.0183 /$ unemployment (after) 


\section{- $\quad$ R-squared}

The R-squared before crisis is $18 \%$. It means that the percentage that the relation between inflation and unemployment rate can be explained by the function is $18 \%$.

The R-squared after crisis is $26 \%$. It means that the percentage that the relation between inflation and unemployment rate can be explained by the function is $26 \%$.

\section{- Relation}

There is a positive relation before crisis. Unemployment rate has little to do with inflation, because inflation is rising with house prices but not with the unemployment rate. After crisis, there is a negative relation, which is consistent with the theory.

\section{FINDINGS AND DISCUSSIONS}

\subsection{Policy Analysis}

In this case, the two best polices to implement are expansionary fiscal policy and contractionary monetary policy. By using expansionary, the government cuts taxes and increases government expenditures and transfer payment. By using contractionary fiscal policy, the government decreases monetary supply and increases discounting rate[3].

\subsection{Reason}

Firstly, during inflation, government needed to ensure that people can meet their basic needs, so they chose to decrease taxes and increase the transfer payment. So it is necessary for the government to use money to subsidize people.

Since the interest rates were relatively low, people spent most of their money and did not save money. That was why the government decreased monetary supply latter. At the same time, they also raised interest rates to encourage people to save money in the bank, so the government got money back.

\section{CONCLUSION}

As Tudor(2009) said, before 2006, with the sharp increase in prices, the U.S. real estate market showed all typical signs of "boom" or overheating[4]. Meanwhile, buyers' acceptable credit scores have fallen, and unit risk ratio prices have fallen, especially mortgage loans[4]. The level of total loan value recorded, the ratio of residential real estate to annual rent equals the PE ratio of the equity[4]. In addition, with the significant spread of asset-backed securitization, rating agencies failed to find the imminent danger of high leverage in the system, and the leverage ratio of homeowners and financial institutions was higher than ever before. The so-called subprime expansion continued to push up house prices to unprecedented height. The trend of rising house prices masked the deterioration of borrowers' quality. As a result, the credit crisis broke out. In April 2007, New Century Financial, which specializes in subprime mortgages, applied for bankruptcy protection. This event officially opened the curtain of Sub-Prime Debt Crisis. This article mainly explores the feasibility of Phillips curve in Sub-Prime Debt Crisis by using a panel data approach. The empirical result in the article shows that Sub-prime debt Crisis does accord with the features of Philips curve, but this phenomenon only exists in a short run. There might be some other factors that influence the relationship between inflation and unemployment. Besides, the author also explains the impact of the different government policies aimed at rescuing financial recession. More specifically, the two types of policies that government should have implemented are expansionary fiscal policy and contractionary monetary policy. Theoretically, these two policies have a positive impact during the recession. In brief, financial linkages must be understood. According to Khor and Kee(2008), the complexity and connectivity of financial markets and products have during the subprime crisis become increasingly apparent[5]. Policymakers and regulators should have the right decision on policy in order to rescue the paralyzed economy. A healthy, long-term growth prospect can be defined as the region is poised to ride, or even lead, the next economic boom. The challenge is to ensure that its development will not be affected by financial land mines along the way. Therefore, the above is what we can learn a lesson from of Sub-prime Debt Crisis. What we need to do is to learn from the mistakes and then make further efforts[5].

\section{ACKNOWLEDGEMENT}

First and foremost, I would like to show my deepest gratitude to my teachers and professors in my high school, who have provided me with valuable guidance in every stage of the writing of this thesis. Further, I would like to thank all my friends and roommates for their encouragement and support. Without all their enlightening instruction and impressive kindness, I could not have completed my thesis.

\section{REFERENCES}

1. X. Xu. Getting inspiration from American Subprime Mortgage Crisis Towards Chinese Financial Supervision, Nanjing University of Science and Technology, Mar. 2011, vol. 19, no.1, pp.4

2. Y. Zhao. Analysis of the US Subprime Crisis and Its Transmission Mechanism. Journal of Bayin Guolen Vocational and Technical College, 2009, 000 (002), pp.44-45.

3. P. J. Wallison. Cause and effect: government policies and the financial crisis. Critical Review, 2009, vol. 21, no. 2, pp. 365-376.

4. C. Tudor. Understanding the Roots of the US Subprime Crisis and its Subsequent Effects. 
Romanian journal of economic forecasting, Janus 2009, pp. 35.

5. H. E. Khor, R. X. Kee. Asia: A perspective on the Subprime Crisis. Finance and Development, June 2008, pp. 23 